\title{
Ethnomathematics of Indigenous Peoples of the North
}

\author{
Galina D. Tereshkina \\ North-Eastern Federal University named after M. K. Ammosov, 677000, Yakutsk, Russia \\ Email: tgd-imi@yandex.ru \\ Nadezhda I. Merlina \\ Svetlana A. Kartashova \\ Chuvash State University, 428015, Cheboksary, Russia \\ Motrena D. Dyachkovskaya \\ North-Eastern Federal University named after M. K. Ammosov, 677000, Yakutsk, Russia \\ Natalia A. Pyryrco \\ Chuvash State University, 428015, Cheboksary, Russia
}

Doi:10.5901/mjss.2015.v6n2s3p233

\section{Abstract}

Education of the value to a particular society in the Northern regions of the Russian Federation is connected with socio-cultural and economic transformations in the places of dense residence of small-numbered peoples of the North, which leads to the necessity of improving the system of upbringing and education of children in encampments. In this regard, the process of education should organically include axiological aspects of human life: the interiorization of nomadic peoples' values, ensuring the development of a student's personality. The article discloses the content of the regional-ethnic component of mathematics education in which the learning content is in unity with the basics of mathematical science and ethnomathematics of indigenous peoples of the North. The leading approach to study this problem, allowing to identify the main content of the course "Ethnomathematics" of the regional-ethnic component, is the analysis of scientific, educational, fiction literature and systematization of the knowledge accumulated by many generations (astronomical, phenological, economic) and elementary issues on the development of numbering, mathematical terminology, the emergence of measures associated with a unique culture and traditional economic activities of the nomadic peoples of the North. The main results of the article: ethnomathematics was being formed by the course of the history of the region's reclamation, was being enriched by the adaptive features, as well as by the spiritual and economic practices of the Northern peoples. It is possible to talk about the viability of the proposed contents of the specialized course "Ethnomathematics" of the regional component in the regions of Russia with the indigenous small-numbered peoples of the North.

Keywords: indigenous education, ethnomathematics, North indigenous ethnic groups, numbering of numbers, mathematical terminology, measurement of sizes.

\section{Introduction}

\subsection{The relevance of the problem}

Mathematical education is compulsory and an integral part of general education at all the levels of education. Currently, within the study of mathematics in schools a national-regional component is being widely implemented in the areas of: a) personal development: the formation of ideas about mathematics as a part of universal human culture; $b$ ) in the metadisciplinary area: the development of ideas about mathematics as a form of description and a method of cognition. The formation of the content of the course "Ethnomathematics" of the regional component should be systematized in values stored in the religious, cultural, socio-historical, family traditions of nomadic peoples, transmitted from generation to generation and providing personal development. The content of the specialized course "Ethnomathematics" should be 
aimed primarily at students' interiorization of cultural values, arming them with knowledge about the natural environment, distinctive activities of the nomadic peoples of the North (Tereshkina, 2013).

\subsection{The importance of the research problem}

Pedagogical understanding of the current educational situation in the places of dense residence of indigenous smallnumbered peoples of the North in the study of the regional component courses leads to the search for introduction of a section into the content of the educational subject "Mathematics", which explores the values, lifestyle and unique culture of the Northern peoples, in which mathematics occurs. An example of a regional education is a mobile form of the school network - the nomadic school, aimed at meeting the needs of Northern peoples in quality education and development of children, taking into account individual motives, educational interests of students, values, traditions and unique culture of nomadic peoples in places of their dense residence in Yakutia (Tereshkina, 2013). The organizational integrity of the educational environment of nomadic schools acts as a result of implementing the variable (regional-ethnic) component of education as the interiorization of values, traditions and experience of the original activity in the life of nomads. In this context, to implement the substantive content of the regional-ethnic component of training of the specialized course "Ethnomathematics" the systematization of mathematical knowledge and views of the Northern peoples of Russia is required, from the point of view of elementary issues on the development of concepts of number and numbering of numbers, the distinctive terminology, the emergence of measures as an important social experience of nomadic peoples, adapted to be passed down from generation to generation.

\subsection{Features of nomadic education of small-numbered peoples in the North}

We define the nomadic education as "the means of intellectual, spiritual, and social development of indigenous peoples tested for centuries on the traditions and cultural values with regard to the principles of their activity and lifestyle in the North of the Russian Federation" (Tereshkina, 2013). The core of the nomadic education is students' interiorization of values, norms, and behavior patterns. Conscious acquisition, preservation and enhancement of the experience of the traditional activities of the nomadic people are that foundation which unites the generations together. The system of nomadic education includes the nomadic school, the family community, the development Center of the nomadic educational institutions of Yakutia, the Centre for distance education in Yakutia. The main purpose of ethnomathematics - is the study of culture, in which mathematics occurs (the term "ethnomathematics" was introduced at the fifth congress of ICME (International Congress on Mathematical education) - it is to teach students to solve problems that arise in reallife situations, using knowledge, training and life experiences, values of the nomadic peoples of the North.

\subsection{The status of the problem}

The requirements of the nomadic peoples of the North for the results of education are much more complicated than a simple evaluation of the received knowledge. The main problem of the educational theory and practice of the nomadic education is the lack of science-based development of the course content of the regional-ethnic component of the educational subject "Mathematics" in nomadic schools, where the foundation for personal development is laid, due to the specific role of ethnicity: "function or behavior pattern objectively given to an individuum in the system of social and interpersonal relations" (Mudrik, 1986). The term of "ethnomathematics" first appeared in the second half of the last century in the works of a Brazilian mathematician U.D'Ambrozio, who used this term as "... a specific encoding tool that enables the members of a particular culture to not only describe but also to understand the reality and to manage it..." (Diachkovskaia, 2014). The idea of belonging of mathematics to the field of culture is allocated as follows: the foundation contributing to the specificity of mathematical knowledge and culture of a particular social group as a whole is a traditional everyday practical activity, prevailing in it (Yashin, 2013). In the selection of the content of the specialized course of the regional-ethnic area the reliance on the following theoretical propositions was realized: "the purpose of education - is to prepare children for participating in the activities of human society" (A.V. Borovskikh, 2010), the source of the content formation of general education is culture - as the most important form of social and cultural experience (V.V. Kraievskiy, 2013). The analysis of the works of the aforementioned authors and other publications on the topic has shown that the problems are related to the study of the history of development of the common knowledge of the nomadic peoples in the North, giving the opportunity to form a view about mathematics as a part of universal human culture. 


\subsection{The research hypothesis}

The analysis of the theoretical works and practical activities in the aspect of the problem being developed showed that issues related to regional characteristics of teaching students in the conditions of the specialty "Teacher education" remain as the understudied area of scientific knowledge and practical activities today, which enabled us to formulate the hypothesis of the research of this problem: the content of the professional education of the students majoring in "Mathematics" would be more effective if the content of the regional-ethnic component was developed for the "History and methodology of mathematics" course and the possibilities of the regional cultural and historical learning environment were used in the places of dense residence of indigenous small-numbered peoples of the North.

\section{Materials and Methods}

\subsection{Theoretical and empirical methods}

To test the hypotheses the following research methods were used: theoretical - analysis and generalization of scientific, educational literature and fiction on the research problem; the systematization of the accumulated knowledge of many generations (astronomical, geographical, phenological, economic) and elementary issues on the development of numbering, mathematical terminology, the emergence of measures associated with a unique culture and traditional economic activities of the nomadic peoples of the North. Empirical - are observation, interviews with high school students, college students, members of the nomadic community.

\subsection{Mathematical culture in the life and folklore of indigenous small-numbered peoples of the North}

In the book "History of mathematics in ancient times" it is stated that the primitive tribes of nomadic pastoralists needed guidance when moving over the vast steppes. Thus their observation of the movement of the stars began" (Kolman, 1961). In the work "The Chukchi. The religion" the issue about the astrological views of the Chukchi is dealt with, as well. They were engaged in observation of the sky, watched the movements of the celestial bodies also in winter, when the sun does not appear at all, used them as landmarks (Bogoraz, 1934). In the work "Paths of the Millennium" it is noted that all celestial bodies, constellations and stars had their names among the Northern peoples and are linked to the visually observed position of the object (Keimetinov, 2000). The ancestors of the modern evens (the Evenkis, as well) have marked the main, visually noticeable feature in the stars, namely, that they seem to leap, jump, fly away, in other words, blinking. The confirmation is found in the meanings of the words ocikaht (the Evens'), osikta (the Evenkis') meaning "leaping", "jumping", "flashing". Names of stars are most often associated with the mythical ideas of nomadic peoples about the origin of these stars: Hawak hetaranni 'tracks of the hunter's skis' - the Milky Way, Dierlakachan udyan 'rabbit trail' - a group of stars of the Little Dipper, and so on. The analysis of the literature showed that the Evens had calculus of months through various parts of their bodies. The calculus of months was meant to begin with the crown of the head in a circle, strictly following the visual solar motion around the earth, listing the names of the main parts of the human hands and both shoulders, that was available to everyone in the same period of the historical development. The counting begins with January: toganee haian "the height, the top, the top of the land", evry mir "the sloping shoulder", evry echen "the descending elbow", evry bilan "the descending wrists", evry unma "descending hands", evry haialra "the descending fingers", diugani heien "the height, the top, the peak of summer", aucheri haialra "the bottom-up joint of the finger", aucheri unma "the rising hands", aucheri bilan "the rising wrist", aucheri echen "the rising elbow", aucheri mir "the upside shoulder" (Vinokurova, 2006). An Even had just to remember what part of his body he got at when counting months and, replicating the counting, starting from the top, again to find the desired month. Traditional economic activities of the Evens demanded empirical generalizations, sensory counting in reindeer terminology, associated with the fixation of the age and sex of deers: ankan 'fawn under 6 months', namukan 'she-deer under 1 year', eni 'she-deer of 1 year, having calved', khatti 'she-deer - doe of 1-2 years', iavkahn 'calf of a domestic reindeer of 1-2 years', iitian 'three years', moika 'a deer male of 2-3 years', nyorkahn 'deer-male of 4 years', nehrkahn 'four years', khavdi corbeh 'deer-male over 6 years of age' (Vinokurova, 2006). As we move to a higher level of the development, the "sensory" counting turns out to be insufficient. There arises the need to compare multitudes, comparing elementwise their number, for example. This need manifested itself mainly in the process of communication between people and their exchange operations. Originally the exchange was not of the transaction nature. So, until 1931, there was no trade between the Dolgans. The one in need of some things came to one who had that thing, begged for it and always got this thing for free. But later, the one who gave the thing, in case of any need, could address the recipient, and the latter was to give what was asked for". If a thing was not 
expensive, was not equivalent to the deer, the Dolgans usually would say when selling: "We don't know how much you give, so much is okay" (Popov, 2003). This way a mutual exchange happens, that is not limited by time and not determined by equal value of the exchanged objects (things). An idea about the quality of the exchanged items, their weight, size, etc., did not yet play a decisive role. Per pound of tobacco one had to pay from ten to twenty squirrels, for a brick of tea - 20 squirrels, a firelock - 200 squirrels, a Yakut knife - 10 squirrels, a pricket - 20 squirrels. Smallnumbered peoples of the North in the choice of units of measurement intuitively used the dimensions of parts of the human body, although the inaccuracy, instability of such kind of units is obvious. The Evens' length standards were the following measurement units: "togahr" 'the distance between the thumb and the forefinger at their outer position', "echen" 'a distance equal to the elbow of a man', "dar" 'a distance equal to the length of the outstretched hands', "dar gadan" 'the distance from the middle of the chest to the end of an arm's length', "tomka" 'a distance equal to one-step' (Shadrina, 2014). The smallest unit of length measurement among the Dolgans is: black nails - the dirt strip size under the nail. When measuring the height (the depth) the Dolgans' measurement unit is also the dimensions of the parts of the body: "the mountain cracked open so that one little finger fits it"; "with this the mount opened as widely as a palm; a wolf cub came out up to the waist, and the bear cub was so out that his back was shown"; "about eight joints to pinch horsetailgrass"; "into the frozen ground leaving knee-high". In the olango (a tale) "a Brave Okwolai" it was said: "... sister, standing in front of his brother, was with such words: "The more Yakuts there are according to the length of the gun, the better people there are judging by the length of the string", and so saying, you were exalted..." (Popov, 2003). Here other measures are mentioned, related to hunting of nomads "the length of a gun", "length of string". To measure the length of a great length, the distances, which approximately could be passed for a certain (but not exact) period of time, served as the measurement units. Such length measures among the Evens, for example, were: "nulgae" distance for one migration (about $25 \mathrm{~km}$ ), "chayat" - the distance traveled without stopping, about 30 km (Tereshkina, 2013), "kunikich" - 'distance, where the cry comes' (Shadrina, 2014). In the tale "the King's tasks" there is description about a bird ysaai-tumaraahn (eagle): "A sharp-sighted bird, notices at a distance of nine nights (about $125 \mathrm{~km}$ ), even if the deer hair falls..." (Popov, 2003). The Nenets used such concepts as migration during the winter to determine the length and distance (syerah khun - nenets.), within so many days (yalakhun - nenets); the distance that people are passing on deers without rest - 7-15 km (nedalava - nenets.), the distance from the shooter to the target $(150-200 \mathrm{~m})$, the distance at which the subject (e.g., chum) is visible with the naked eye; the length of the roping - 15-20 m (Pyryrco, 2014). The analysis of the literature shows that small-numbered peoples of the North used their own measures of weight for weighing. The Dolgans had the replacement of measuring the weight of food and fluids by comparing the respective amounts of household items. To store dried meat chopped into small pieces (elyuktae - dolgan.), sun-cured Pacific salmon (diouukala-dolgan.) and crushed dried fish (puorsa - dolgan.), which were used as a snack for tea, the outaki was used - bags made of burbot skin. Deer or goose fat was kept in the deer bladder, and in the stomach of a big fish, mainly Kundscha, only fish oil was kept. The measures known to the Yukagirs, "chuoraskae douun" - the contents of one boiler, "loogouroobull Touul" - the contents of the tray (i.e. what fits into the tray of the skins sewn together, "peagae touul" - the content of the birch bark boxes intended for boiling water). Also common is the approximate estimate of the heaviness by comparing with the traction power of the deer: "paraah" - the content of the sled, which is barely being pulled by two deers, "vaelyl" or "newmurdongoi" - the deer pack (saddle bag), the weight is meant that can be carried by a pack deer, "tudaenial" - the cart that can be carried by a reindeer-drawn sled (Diachkovskaia, 2014). The Nenets' units of volume were the capacity of the boats, sleds, deer stomach (filled with fish oil, was considered to be at a price equal to one deer). For some spatial images there were very few abstract concepts, which is a natural support for learning the basics of science. The dolgan terms denoting mathematical concepts: diala cyr - 'place and space', tas - 'surface', ouhouna - 'length', urdyugae 'height', ugyus - 'many, much', and so on (Aksenova, 1992). The Yukagirs had the following geometric concepts-terms: "Pura5a" - 'surface', 'sabirkha" - 'plane', "chougounmae" - n. 'corner', "vakhchae" - noun. 1) face, sharp side; 2) edge, face, side of something; 3) the edge, the edge of the eye, "pomorkae"- n. 1) ring, circle; 2) fastener, loop, "pomneiroukoun" - n. 'a round thing', "ponkhataah" - n. 'something convex like a ball', "ordialaldanout" - as a noun 'he who is in the center (in the middle), located in the middle, in the centre', "ordian" - 'in the middle; in the central part of something', "samnae" - 'to be flat' and et cetera (Diachkovskaia, 2014). The aesthetic needs of indigenous smallnumbered peoples of the North played an important role in the development of geometric ideas: the desire to decorate household items, clothes, themselves. In ornamental art the dolgan symmetry is used as the main tool to create a visual effect associated with the movement, time and space. In the ornaments there are three symmetric transformations: the reflection, the rotation in the rosaces and the parallel transferal at the border organization of the ornament. Upon reflection, or mirror symmetry, there is an imaginary plane which divides the figure into two secularly equal halves and is called the "plane of symmetry". The alignment by rotation is associated with the "axis of symmetry" (Ryndina, 1995). The motives for the ornaments are taken from the environment "rabbit ears", "antlers", "broken antlers", "elk antlers", "cow 
horns", "brands" (Pyryrco, 2014).

\section{Results}

\subsection{The regional component of the curriculum subjects in the area of the "'mathematics" teacher education profile".}

In the process of learning the disciplines of general and special cycles, the following manuals were developed and implemented in the educational process: "the History of mathematics" (numberings of various peoples of the world" (Merlina, 2009), "a Collection of problems according to the methods of teaching mathematics on the basis of folklore and local history material of Yakutia", (Petrova, 2011), "Folklore and local history mathematical problems of the peoples of Russia" (Merlina, 2012), "Mathematics and Informatics" on the basis of historical, folklore and local history mathematical problems (Kartashova, 2013), "Ethnomathematics of indigenous small-numbered peoples of the North (the Yukagirs). Historical, folklore and local history mathematical problems of the upper Kolyma river and the lower Kolyma uluses of the Sakha Republic (Yakutia)" (Diachkovskaia, 2014), taking into account the regional component, the primary purpose of which is to build the basic knowledge of students and to develop personality motivation for the knowledge of the way of life, distinctive culture and values of the indigenous peoples of the North. The developed training manuals of the disciplines (courses) in the field of "Pedagogical education" study, maximally implement the principle of cultural congruence, which is reflected by virtue of its uniqueness and special inner strength, as cultural-historical traditions are still alive and revered, the indigenous culture and nomadic way of life, basically, have been preserved, the spiritual legacy still affects the mindset of people (Tereshkina, 2013) and that responds to the content of training students majoring in "Teacher education" in the region with the nomadic peoples of the North. The textbooks of the course "History and methodology of mathematics" in special and professional cycles disciplines were examined by the Ministry of education and science of the Russian Federation and recommended for use within the specialization 050100 "Teacher education" ("mathematics" profile). Under the guidance of teachers, the students develop and apply creative problems on folklore and local history material, which are used as a means of learning and cognitive activity in the acquisition of mathematical knowledge, in which the learning content acquisition is in unity with the creative work of extraction of the scientific information accumulated in the history of the people. Of particular interest is the educational work on teaching problem solving to children of the indigenous peoples of the North in a health sanatorium "Bas Chagda" (Yakutsk).

\subsection{The content of the regional-ethnic component of the course "History and methodology of mathematics" of "Teacher education" training in the field of "Mathematics"}

The leading approach to the study of this problem, making it possible to identify the main content of the specialized course "Ethnomathematics" of the regional-ethnic component, is to organize common knowledge of the Northern peoples and elementary issues on the development of numbering, mathematical terminology, the emergence of measures associated with a unique culture and traditional economic activities of indigenous peoples of the North. A necessary component of the mathematical culture of a person is a general familiarity with the methods of cognition - from simple, digestible in direct experience, to the assimilation of the idea of number and symmetry, the perception of geometric shapes, the space. Mathematical culture of the peoples of the North was being formed by the course of history of the region's exploration, was being enriched by adaptive features, as well as by spiritual and economic experience of the people. Astronomical views of the Northern peoples reflect features of their thinking, show the contemplative nature of the Northern people's perception of concepts related to space and time. The people of the North have three main types of calendar systems: based on the alternation of the moon phases (the Dolgans, the Yukagirs), natural-economic principle (the Evenks), the calculus of months through various parts of one's body (the evens). In the process of production activity a person gets to know the world, i.e., reflects in his consciousness the surrounding objects and phenomena. For nonliterate peoples, it was important to consolidate the results of observation in the memory of a person, the formation of notions and concepts. "A number" is empirically the first concept of mathematics; it is in the basis of mathematical knowledge of nomadic peoples. Manual count played the same important role in the development of counting as the discovery of fire in the overall development of a primitive man (Kolman, 1961). Perhaps, the first act of finger counting was the indication of a subject by the index finger; here the finger played the role of the unit (Merlina, 2009). Each of the peoples of the North gradually came to the necessity to go to the fingers of one's own hand as a counting tool. In the numbers of irkin (one), atakhun (two), yelokoun (four) and kounal (ten) in the Yukagir language there is the syllable "kin", "koun", "khuun", which means "a finger." So, five (niakhanboy) is related to the word khanbo (a palm, a wrist, a hand, i.e. five fingers). Niakhani-boi (five) - presumably, a wrist, a hand. Kunael (ten) means "fingers all together", i.e., ten 
(Shadrin, 2014). The number is perceived as one of the properties of the set of objects that characterize this set along with the other properties: color, shape, size, and so on (Bashmakova, 1951). The numerals represent a vast reservoir of folk vocabulary of the Northern peoples, which contributed to the formation of a numeric range. A large number of items for which there were no appropriate terms - names of numbers, the Yukagirs estimated by comparing with the number of stars in the sky. Description of great wealth in folk tales (olongo) of the Dolgans "Brave Okwolai" is written by the words "He owned so many cattle that the sun was blacked out by dew because of the cattle's breath, by so much, that the moon was covered by the smoke fog from the evaporation of the livestock". The nomadic peoples of the North, when counting, mostly used only whole positive numbers. They understood that an odd number - is "chorbo5tauhokh bouolar" (lit. it happens with the remainder). A daughter-in-law - an Evenki, should wear dresses in three layers. The bottom of the outerwear (coat) of the daughter-in-law must be sheathed by three fur pelts. A future daughters-in-law was required an odd number of fur coats 7-9, an odd number of deers - 117 or 201 (Anisimova, 2010). In the oral epic of the Dolgans (olongo) "Brother and sister" (Popov, 2003) fractional numbers (fractions) are mentioned: "A monster sings: "Your top will split into six, your bottom - will rip into three...". The Yukagirs knew about a half and a quarter: ynuunchyevipyt, ygaechyyapyt 'half', gyenounaeta 'in half', pytvychyvipyt - 'a quarter', chyviptygivin - 'half a year' (Diachkovskaia, 2014). The history of the numbering had begun with the first attempts of a man to systematize the surrounding numbers. Different groups of numbers had been tried. So there appeared the binary, the tertiary, the five- and sextuple systems, ten- and duodecimal, sexagesimal number systems and others (Merlina, 2009). The Yukaghir counting system is based on two principles - the fivefold and tertiary. On the one hand, number three is taken as the basis. Four (ye'lokoun and ya'lokhloi) means three and one; six (malhi'ialoi) - is twice three; seven (purki'oi) - is one more than six; eight (malhi'yalokloi) means twice four. Kunael (ten) means "fingers all together", i.e. ten. Niakhani-boi (five) - presumably a wrist, a hand (Jochelson, 2005). The vigesimal system arose from the people, who count not only using fingers, but also toes. Chukchi sometimes take off their shoes, and the score is twenty fingers and toes. Five people are a hundred (Semoushkin, 1970). There was irregular, random matching between two sets (between sets of items in exchange). In the absence of writing among the peoples of the North there were no special characters for numbers. The results of the generalization of the mathematical culture of the indigenous peoples of the North testify to the effectiveness of the implementation of the contents of the regional component of general professional and special disciplines in the field of "Teacher education" promoting knowledge of lifestyle, distinctive culture and values of the indigenous peoples of the North.

\section{Discussion}

The problems of mathematical culture of indigenous peoples of the North (ethnomathematics) are considered by Merlina N.I., Kartashova S.A. (Chuvashia), Petrova A.I., Tereshkina G.D., Diachkovskaia M.D. (Yakutia), Pyryrco N.A. (Yamalo Nenets autonomous District) and others. The history of numbering the peoples of the world, folklore and local history problems of the peoples of Russia living in Adygea, Astrakhan and Arkhangelsk regions are well represented in the works of N.I. Merlina; organization of independent work of humanity department students in the study of the course "Mathematics and Informatics" on the basis of historical, folklore and local history mathematical problems is covered by Kartashova N.A. and Merlina N.I., the origins of mathematical knowledge and understanding of the peoples of the North, from the point of view of mathematics teaching methods on folklore and local history material about Yakutia are set forth in the works of A.I. Petrova (the Yakuts), Diachkovskaia M.D. (the Yukagirs) and Pyryrco N.A. (the Nenets), studies of Tereshkina G.D. are devoted to the organizational-pedagogical conditions of the Russian North-East nomadic peoples' specialized education. The considered aspect - the inclusion of the specialized course "Ethnomathematics of indigenous minorities of the North" in the professional training of future mathematics teachers, was not considered in previous studies. In our work we have tried to systematize traditional knowledge of the indigenous peoples about the world as a distinctive ethnic value stored in the religious, cultural, socio-historical, family traditions and to correlate it partially with the history of elementary mathematics.

\section{Conclusion}

In the tutorials of Diachkovskaia M.D. and Pyryrco N.A. the history of the mathematical culture in the life and folklore of the Northern peoples is described. In the folklore the objectivity of the world is seen not in the usual to a modern man theoretical formulation: "the matter is primary, the cconsciousness is secondary", but in a form of a series of generalizations from the practice of life: (a) the numerals constitute a vast reservoir of folk vocabulary of the Northern peoples that contributed to the formation of a numeric range; empirically, the first concepts of mathematics are in the 
basis of the economic activities of the indigenous peoples of the North; b) oral numbering of the Northern peoples was based on binary, ternary, fivefold, nonary, decimal, and vigesimal number systems; c) there was an irregular, random matching between two sets of objects in the exchange; d) the peoples of the North had peculiar ideas about length measuring, volume, weight; d) the indigenous small-numbered peoples of the North have used the peculiar measurement units: they intuitively used the dimensions of parts of the human body; the capacity of items for household, transportation, storage, hunting, catching birds, etc.; e) the source of the content formation of nomadic education is a distinctive culture, i.e. the most significant forms of the experience of traditional farming transmitted from generation to generation. The proposed content of the regional-ethnic component of higher professional education of students in the field of "Teacher education" of the "Mathematics" profile meets the following principles: cultural congruence, analogy in the logic of correlation with the relevant concepts and terms of the mathematical science, the developmental education, where the kernel is the axiological aspect - the interiorization of the cultural and historical heritage of the indigenous peoples of the North; problems on folklore, local history and historical material of the indigenous minorities of the North are used as a means of educational activity of students in mastering mathematical knowledge, in which the learning of the content is in unity with the creative work of extraction of scientific information in the focused intellectual work on the composition of a wide range of mathematical problems; the cognitive activity is expressed in the formation of value systems and in the conscious mastery, preservation and enhancement of the life experience of the indigenous peoples of the North.

\section{References}

Aksenova, E.E., Beltyukova, N.P., Kosheverova, T.M. (1992). The Dictionary of the Dolgano-Russian and the Russian-Dolgan languages: SPb.: St. Petersburg, 192.

Anisimova, M.A. (2010). Oloon-Uran Hauiuun araana (Olenek - home of Uran Khosun). Yakutsk, Bichik, 212.

Bashmakova, I.G., Yushkevich, A.P. (1951). The origin of number systems. Encyclopaedia of elementary mathematics. V. 1. Arithmetic. (V.1, pp. 11-74). Moscow.

Bogoraz, V.G. (1939) The Chukchi. The religion. The authorized translation from English, edited by Y.P. Frantsov. Leningrad, The Northern Sea Route, 6

Borowskikh, A.V., Rozov, N.Kh. (2010). Active principles in pedagogy and the pedagogical logic: a Handbook for vocational teacher education, retraining and training of scientific-pedagogical personnel. Moscow, MAKS Press, 80.

Diachkovskaia, M.D. (2014). Ethnomathematics of the indigenous peoples of the North (Yukagirs). Historical, folklore and local history mathematical problems of the upper Kolyma river and the lower Kolyma uluses of the Sakha Republic (Yakutia): the manual. Yakutsk, 114.

Federal state standard of secondary (complete) general education. (2013) Moscow, Prosvecheniye, 63.

Jochelson, V.I. (2005). Materials for the study of the Yukagir language and folklore collected in the Kolyma district. Yakutsk, Bichik, 271.

Kartashova, S.A., Merlina, N.I. (2014). Independent work of students of Humanities Departments in the study of the course "Mathematics and Informatics" on the basis of historical, folklore and local history mathematical problems. Informatization of Education: 2013 the proceedings of the international scientific - practical conference (pp. 145-149). Volgograd, Russia.

Keimetinov, V.A. (2000). Along the paths of millenia. Yakutsk, 180.

Kolman, E. (1961). The history of mathematics in antiquity. Moscow, 235.

Kurilov, G.N. (1999). Formation of nominal words in the Yukagir language. Leningrad, Institute of problems of indigenous peoples of the North, 104.

Merlina, N.I. (2012). The folklore and the local history mathematical problems of the peoples of Russia.. Cheboksary, 290.

Merlina, N.I., Popova, N.Ya., Merlin A.V. (2009). History of mathematics: the numbering of various peoples of the world: a manual. Cheboksary, 116.

Mudric, A.V. (1986). Teacher: Skill and inspiration. Moscow, 160.

Petrova, A.I. (2011). A collection of problems on the methods of teaching mathematics based on the folklore and local history material of Yakutia: a training manual. Yakutsk, 66.

Popov, A.A. (2003). Dolgans. The collection of works on Ethnography. (2003). St. Petersburg, 319..

Pyryrco, N.A. (2014). The life of the peoples of the Far North (Nenets) in mathematical problems. Cheboksary, 106.

Ryndina, O.M. (1995). Essays on the cultural genesis of the peoples of Western Siberia. Tomsk, 640.

Semoushkin, T.Z. (1970). The selected works. Moscow, Fiction, 104.

Shadrin V.I. The Ukagir Country. Be inroduced: Nelemnoye. http://www.nlib.sakha.ru/knigakan/index.php/tematicheskie-kollektsii/ territorii-kompleksnogo-prozhivaniya-mns/respublika-sakha-yakutiya/568-strana-yukagiriya.html

Sharina, S.I. (2013). The Lexical means of expressing quantitativeness in the Even language: 2013 - the proceedings of the seventeenth international correspondence scientific-practical conference "Innovations in science". Novosibirsk: "SibAK" Publishers (142-146).

Tereshkina, G.D. (2013). Organizational-pedagogical bases of specialized education in the schools of numerically small peoples of the North in the Russian Federation (thesis). Kaluga, Russia.

Vinokurova, U.A. (2006). Art and culture of the reindeer herding peoples: 2005 - the proceedings of the international scientific 
conference (pp. 99-101). Yakutsk, Russia.

Yashin, B.L. (2013). Mathematics as a variety of quantitative methods for perceiving the world. Bulletin of MSRU, 2, $6 \mathrm{http} / \mathrm{mww} /$ evestnik-mgou.ru. 